\title{
Long-term outcomes of nail bed reconstruction
}

\author{
Sung Hoon Koh, Youngkee You, Yong Woo Kim, Jin Soo Kim, Dong Chul Lee, Si Young Roh, \\ Kyung Jin Lee, Min Ki Hong \\ Department of Plastic and Reconstructive Surgery, Gwangmyeong Sungae General Hospital, Gwangmyeong, Korea
}

\begin{abstract}
Background There are various reconstructive options for nail bed defects. However, it is challenging not to leave a deformity. In this study, we investigated differences in outcomes depending on the reconstruction method, attempted to determine which method was better, and analyzed other factors that may affect outcomes.

Methods The long-term outcomes of nail bed reconstruction were reviewed retrospectively. We performed three types of reconstruction depending on the defect type: composite grafts of severed segments, nail bed grafts from the big toe, and two-stage surgery (flap coverage first, followed by a nail bed graft). Subsequent nail growth was evaluated during follow-up, and each outcome was graded based on Zook's criteria. The reconstruction methods were statistically analyzed. Other factors that could contribute to the outcomes, including age, the timing of surgery, germinal matrix involvement, defect size, and the presence of bone injuries, were also compared.

Results Twenty-one patients (22 digits) who underwent nail bed reconstruction were evaluated. The type of reconstruction method did not show a significant relationship with the outcomes. However, patients who sustained injuries in the germinal matrix and patients with a defect larger than half the size of the nail bed had significantly worse outcomes than the comparison groups.

Conclusions The results suggest that no operative method was superior to another in terms of the outcomes of nail bed reconstruction. Nevertheless, involvement of the germinal matrix and defect size affected the outcomes.
\end{abstract}

Keywords Finger injuries / Nails / Reconstructive surgical procedures / Surgical flaps
Correspondence: Jin Soo Kim Department of Plastic and Reconstructive Surgery, Gwangmyeong Sungae General Hospital, 36 Digital-ro, Gwangmyeong 14241 , Korea

Tel: +82-2-2680-7637

Fax: +82-2-2615-7218

E-mail:drkim@korea.com

Received: July 26, 2019 • Revised: September 9, 2019 • Accepted: October 18, 2019

pISSN: 2234-6163・elSSN: 2234-6171・https://doi.org/10.5999/aps.2019.00997• Arch Plast Surg 2019;46:580-588

\section{INTRODUCTION}

Nail bed defects frequently result from fingertip injuries. Despite treatment, considerable numbers of these defects result in nail deformities, which can be accompanied by disability and cosmetic issues [1].

Various treatment options exist for nail bed defects, including healing by secondary intention, composite grafts from a severed segment, dermal grafts [2], nail bed grafts from the big toe [3,4], local flaps, and microvascular free nail transfer [5]. However, the reconstructed nail bed should mimic the unique original characteristics of the nail bed to minimize deformities [6].

At our institution, these injuries are treated with composite grafts of the severed segment, nail bed grafts alone, or flaps combined with nail bed grafts, depending on the wound conditions. The treatment algorithm (Fig. 1) was as follows: when a patient 
Fig. 1. Treatment algorithm for nail bed defects

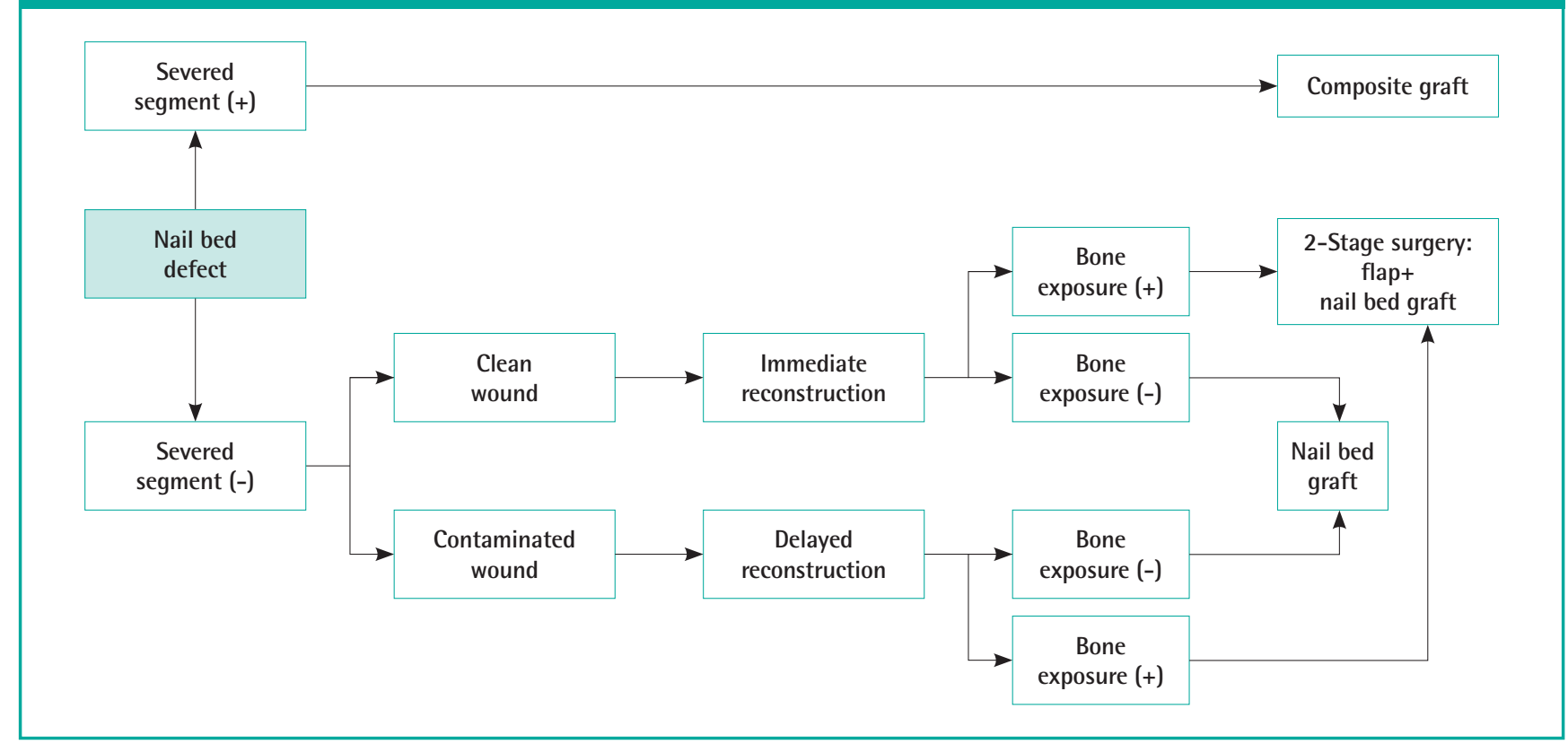

presented with a defect of the nail bed together with the severed segment, we used a composite graft, which may be the best option. If the severed segment was not available, the nail bed was harvested from the big toe for a nail bed graft. If the distal phalanx was exposed with a nail bed defect, a two-stage reconstruction was performed, involving thin flap coverage of the bone first, followed by a nail bed graft [7].

Our previous clinical experiences have shown that even with minor injuries, the results varied from poor to excellent. To establish which reconstruction method may be preferable, a comparative study was conducted to identify differences in outcomes depending on the reconstruction method. In addition, we analyzed other factors that could potentially affect the outcomes.

\section{METHODS}

This retrospective study was approved by the Institutional Review Board of Gwangmyeong Sungae General Hospital (IRB No. KIRB-2019-N-008), and all patients provided informed consent to undergo the procedures. The patients provided written informed consent for the publication and the use of their images. Between August 2014 and March 2018, we selected patients who underwent nail bed grafting from a toe. Cases of composite grafts in which the patient presented with a nail bed defect with a severed segment were also included. However, patients who were lost to follow-up before 6 months were excluded, as were patients with severe crush injuries of the fingertip or bony necrosis from severe infection resulting in shortening of the digits.

Twenty-one patients (age range, 5-58 years; mean age, 37 years; 16 males and 5 females; 22 digits) were evaluated at follow-up examinations. Of the 22 digits treated ( 3 thumbs, 9 index fingers, 4 middle fingers, 4 ring fingers, and 2 little fingers), 12 were on the left hand and 10 on the right hand. The final follow-up examination took place from 6 to 48 months (mean, 12.2 months) from the time of surgery.

The types of reconstructive methods were classified as follows: group 1, use of a nail composite graft when the severed segment was available for repair (3/22); group 2, placement of a nail bed graft from the big toe (13/22); and group 3, a twostage operation requiring placement of a flap and subsequent nail bed grafting $(6 / 22)$ (Table 1 ). The patients in group 3 showed exposed bone or bone defects that were not suitable for nail bed grafting alone. Therefore, we placed a thin flap and subsequently performed nail bed grafting. However, it is not always necessary to perform a two-stage operation in all cases with bone exposure, because grafting the nail bed on the periosteum can provide a result that is better than expected [8]. In our cases, we placed a nail bed graft over the exposed bone when the defect was relatively small. When the area of exposed bone was relatively large or bone defects were observed, a two-stage operation was performed to provide a nourishing bed and to enhance durability. Among the six such cases, the types of initial flap coverage were as follows: a digital artery-pedicled subcutaneous flap (JSK's novel technique to cover defects in the distal portion of a finger) in two cases, a thenar fascial flap in two cases [9], a reverse cross finger flap in one case, and a Becker fascial 
Table 1 . Three groups classified according to the reconstructive method used

\begin{tabular}{|llc|}
\hline Group & Type of reconstruction & No. of patients \\
\hline 1 & Composite graft of severed segment & 3 \\
2 & Nail bed graft from toe & 13 \\
3 & $\begin{array}{c}\text { Two-stage surgery (flap surgery first, and } \\
\text { secondary nail bed graft) }\end{array}$ & 6 \\
\hline
\end{tabular}

free flap in one case.

In addition to the reconstruction method, the following other contributing factors that could affect the outcomes were considered: age, timing of surgery, involvement of the germinal matrix, relative defect size of the nail bed, and presence of bone injuries. Age was divided into 30 years or under (10/22) and over 30 years $(12 / 22)$. The timing of surgery was classified as immediate $(6 / 22)$ or delayed $(16 / 22)$. Involvement of the germinal matrix was evaluated by inspecting previous photographs to determine whether a portion of the lunula was damaged $(9 / 22)$ or not (13/22). Moreover, we classified the patients depending on the size of the defect. The defect size was calculated relative to the whole nail bed as $50 \%$ or under $(11 / 22)$ and over $50 \%$ $(11 / 22)$. Bone fractures or defects were evaluated based on Xray findings at the time of the injury, and patients were classified based on whether they showed bone involvement $(9 / 22)$ or not $(13 / 22)$ (Table 2).

\section{Surgical technique}

After appropriate regional or local anesthesia of the hand was achieved, the hand and the foot (usually on the ipsilateral side) were prepped and draped. Under loupe magnification, irregular edges were trimmed, and the necrotic tissues were conservatively debrided. We then measured the size of the defect, taking particular care to consider the areas of the germinal matrix, sterile matrix, and skin as distinct zones from one another. The toe to be used as the donor was anesthetized using a digital block. After exsanguination, a digital tourniquet was placed for hemostasis, a Freer elevator was inserted beneath the free edge of the toenail, and the nail was raised to expose the nail bed very cautiously to avoid injury to the nail bed. Then, the area of the graft needed on the donor site was marked in the same manner as when we measured the defect, separating the distinct zones. A split-thickness nail bed graft was harvested with a razor blade using a freehand technique; it was placed parallel to the nail bed, and a back-and-forth sawing motion was used to harvest very carefully and slowly. The raised toenail was then repositioned to its original location and secured in place with a nylon 5-0 simple interrupted suture. The graft (matching the longitudinal direction) was sutured into the defect in a simple interrupted fashion
Table 2. Comparison of clinical data according to several factors

\begin{tabular}{|c|c|c|c|c|c|c|}
\hline Case & $\begin{array}{l}\text { Reconstructive } \\
\text { method }\end{array}$ & $\begin{array}{l}\text { Age } \\
\text { (yr) }\end{array}$ & $\begin{array}{l}\text { Timing of } \\
\text { surgery }\end{array}$ & $\begin{array}{c}\text { Germinal } \\
\text { matrix }\end{array}$ & $\begin{array}{c}\text { Defect } \\
\text { size }(\%)\end{array}$ & $\begin{array}{l}\text { Bone } \\
\text { injury }\end{array}$ \\
\hline 1 & Group 2 & 22 & Immediate & & 60 & \\
\hline 2 & Group 2 & 57 & Delayed & & 50 & \\
\hline 3 & Group 2 & 54 & Delayed & 0 & 80 & 0 \\
\hline 4 & Group 2 & 53 & Delayed & & 30 & 0 \\
\hline 5 & Group 2 & 23 & Delayed & & 60 & \\
\hline 6 & Group 3 & 56 & Delayed & 0 & 70 & 0 \\
\hline 7 & Group 3 & 54 & Delayed & & 50 & \\
\hline 8 & Group 2 & 5 & Delayed & & 50 & \\
\hline 9 & Group 2 & 58 & Delayed & 0 & 80 & 0 \\
\hline 10 & Group 3 & 25 & Delayed & 0 & 70 & 0 \\
\hline 11 & Group 1 & 10 & Immediate & & 30 & \\
\hline 12 & Group 3 & 24 & Delayed & 0 & 80 & 0 \\
\hline 13 & Group 1 & 54 & Immediate & 0 & 70 & \\
\hline 14 & Group 3 & 50 & Delayed & & 20 & \\
\hline 15 & Group 2 & 20 & Immediate & & 50 & \\
\hline 16 & Group 2 & 35 & Immediate & & 30 & \\
\hline 17 & Group 1 & 24 & Immediate & 0 & 70 & \\
\hline 18 & Group 2 & 39 & Delayed & 0 & 80 & 0 \\
\hline 19 & Group 3 & 32 & Delayed & & 30 & 0 \\
\hline 20 & Group 2 & 28 & Delayed & & 40 & \\
\hline 21 & Group 2 & 28 & Delayed & 0 & 60 & \\
\hline 22 & Group 2 & 51 & Delayed & & 20 & 0 \\
\hline
\end{tabular}

Table 3. Evaluation of nail bed deformities according to Zook's criteria

\begin{tabular}{|llc|}
\hline Grade & Category & Variation \\
\hline A & Excellent & 0 \\
B & Very good & 1 Minor \\
C & Good & 2 Minor \\
D & Fair & 3 Minor or 1 major \\
E & Poor & $>3$ Minor or $>1$ major \\
\hline
\end{tabular}

with 6-0 absorbable sutures. A nail-shaped piece of a silicone sheet was placed over the grafted site, and a nylon 5-0 horizontal mattress suture was used to hold it in the nail fold. Finally, a compressive dressing or tie-over dressing with an antibiotic ointment was applied in the usual manner as in a skin graft.

\section{Evaluation of outcomes}

Subsequent nail growth was evaluated by reviewing prior medical records, and photographs were available in all cases to assist in the evaluation. Outcomes were graded based on Zook's criteria (Table 3). Each of the five categories (shape, nail adherence, eponychium, surface, and split) was assessed as major or minor, and the final score was calculated based on the total number of major and minor variations as excellent, very good, good, fair, or poor (Table 4). 


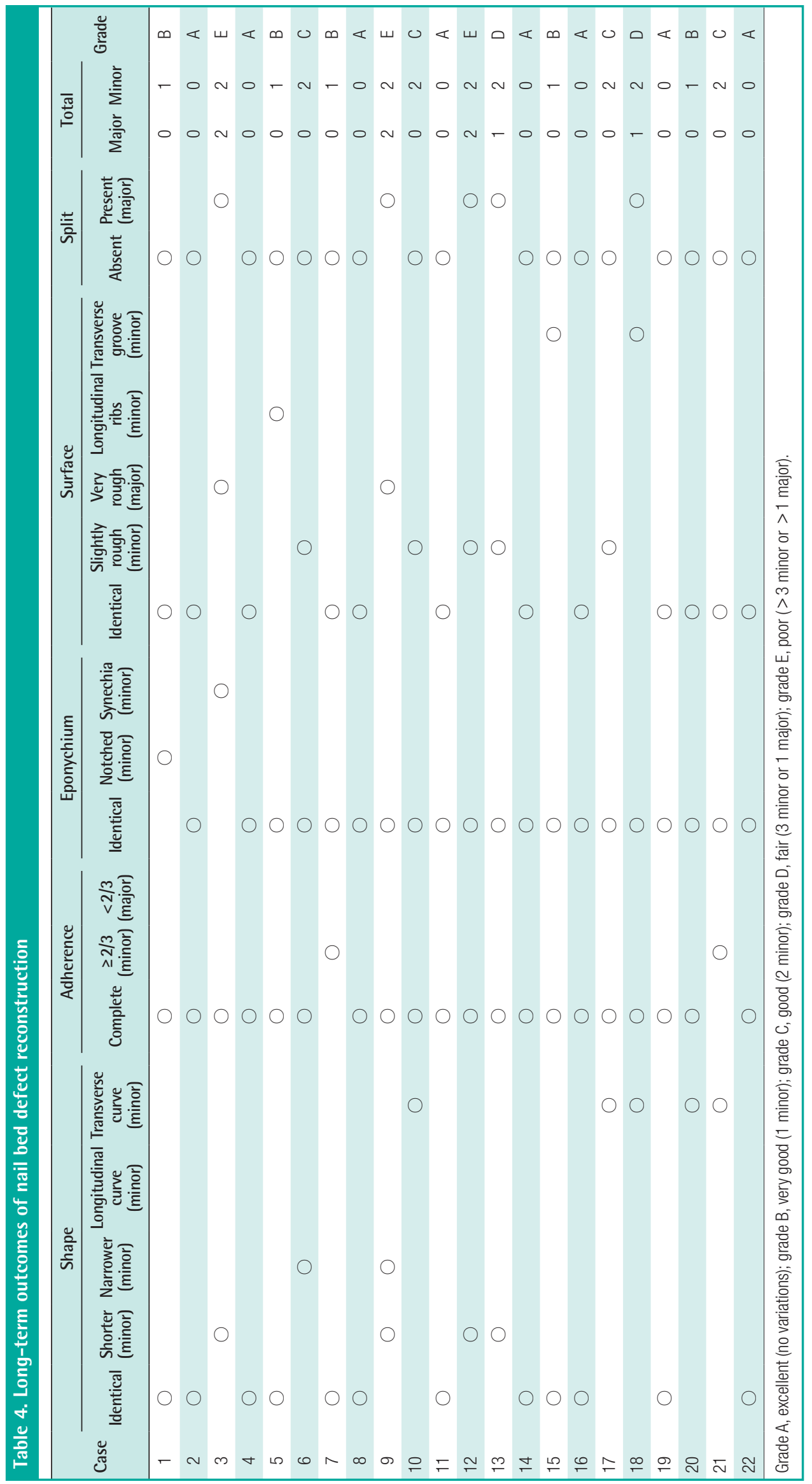




\section{Statistical analysis}

The reconstructive method used, age, timing of surgery, germinal matrix involvement, defect size, and bone involvement were compared based on the outcome grades. Statistical analysis was performed using SPSS version 23.0 (IBM Corp., Armonk, NY, USA) with the chi-square and Fisher exact tests. P-values less than 0.05 were considered to indicate statistical significance.

\section{RESULTS}

All composite grafts and nail bed grafts took successfully. Nail production was observed approximately 4 months after the operation in both the reconstructed finger and the donor toenail. All patients chose to have a nail bed graft harvested from the big toe. The big toes that were used as donor sites showed no functional or cosmetic deficits, except for one case where additional nailplasty was performed because of an ingrown toenail.

The outcomes were excellent (A) in eight patients (36.4\%), very good (B) in five patients (22.7\%), good (C) in four patients (18.2\%), fair (D) in two patients (9.1\%), and poor (E) in three patients (13.6\%) (Table 4).

A comparison of outcomes according to the type of reconstruction method showed no significant relationship $(\mathrm{P}=0.389)$

(Table 5). As there were no remarkable differences in outcomes according to the method of surgery, we analyzed other variables. Age, with patients dichotomized into those 30 years of age or younger $(n=10)$ and those over 30 years old $(n=12)$, was not associated with a significant difference in outcomes $(\mathrm{P}=0.187)$. We compared immediate surgery $(n=6)$ to delayed surgery $(\mathrm{n}=16)$ and found no significant difference in outcomes $(\mathrm{P}=$ 0.645). Patients who sustained injuries to the germinal matrix $(n=9)$ and those who did not $(n=13)$ were compared, and a significant difference was found ( $\mathrm{P}=0.001)$, with damage to the germinal matrix leading to worse outcomes. Patients with defects larger than half the size of the nail bed $(n=11)$ and those with defects smaller than half the size of the nail bed $(n=11)$ were compared; the larger defects showed significantly worse out-

Table 5. Comparison of the outcomes according to the reconstruction method used

\begin{tabular}{|c|c|c|c|c|c|c|}
\hline & Excellent & Very good & Good & Fair & Poor & P-value ${ }^{a)}$ \\
\hline $\begin{array}{l}\text { Reconstructive } \\
\text { method }\end{array}$ & & & & & & 0.389 \\
\hline Group 1 & 1 & 0 & 2 & 0 & 0 & \\
\hline Group 2 & 5 & 4 & 2 & 0 & 2 & \\
\hline Group 3 & 2 & 1 & 2 & 0 & 1 & \\
\hline \multicolumn{7}{|c|}{$\begin{array}{l}\text { Group 1, composite graft from the severed segment; group 2, nail bed graft from } \\
\text { a big toe; group 3, two-stage operation. } \\
\text { a)Chi-square and Fisher exact tests. }\end{array}$} \\
\hline
\end{tabular}

comes than the smaller defects $(\mathrm{P}=0.003)$. Patients with fractures or any bone defects $(n=9)$ and those with intact bone $(n=$ 13) did not have significantly different outcomes $(P=0.144)$ (Table 6).

\section{Case 1}

A 22-year-old man sustained an injury to his right index finger from a kitchen knife. The defect was observed to have a splitthickness depth in both the skin and nail areas. However, the severed segments were missing on arrival; therefore, we planned to reconstruct the portion of the nail bed defect and the skin defect separately. The nail bed graft was designed to match each area of the germinal matrix and sterile matrix within the defect of the nail bed (Fig. 2A and B). A split-thickness skin graft was harvested from the medial longitudinal arch at the plantar portion. At a 24-month follow-up, one minor variation in the longitudinal rib was observed (Fig. 2C), and the outcome was graded as very good (Fig. 2).

\section{Case 2}

A 57-year-old man suffered a crush injury resulting in a soft tissue defect. The distal phalanx was exposed, requiring flap coverage before placement of the nail bed graft (Fig. 3A). We used a digital artery-pedicled subcutaneous flap, our novel technique for covering a defect in the distal portion of a finger. At the distal portion, the terminal digital artery surrounded by sufficient soft tissue was selected and cut at the terminal arcade. Then, the flap was elevated using meticulous dissection on the supraperiosteal plane, preserving subcutaneous perforators as much as possible.

Table 6. Comparison of the outcomes according to several factors

\begin{tabular}{|c|c|c|c|c|c|c|}
\hline Variable & Excellent & $\begin{array}{l}\text { Very } \\
\text { good }\end{array}$ & Good & Fair & Poor & P-value ${ }^{a)}$ \\
\hline Age (yr) & & & & & & 0.187 \\
\hline$\geq 30$ & 6 & 1 & 1 & 2 & 2 & \\
\hline$<30$ & 2 & 5 & 2 & 0 & 1 & \\
\hline Timing of surgery & & & & & & 0.645 \\
\hline Immediate & 2 & 2 & 2 & 0 & 0 & \\
\hline Delayed & 6 & 3 & 4 & 0 & 3 & \\
\hline Germinal matrix involvement & & & & & & 0.001 \\
\hline Not involved & 8 & 5 & 0 & 0 & 0 & \\
\hline Involved & 0 & 0 & 4 & 2 & 3 & \\
\hline Defect size & & & & & & 0.003 \\
\hline Nail bed $\leq 50 \%$ & 8 & 3 & 0 & 0 & 0 & \\
\hline Nail bed $>50 \%$ & 0 & 2 & 4 & 2 & 3 & \\
\hline Bone involvement & & & & & & 0.144 \\
\hline With bone injury & 2 & 1 & 2 & 1 & 3 & \\
\hline Without bone injury & 6 & 4 & 2 & 1 & 0 & \\
\hline
\end{tabular}


Fig. 2. Nail bed graft and skin graft

Case 1. (A) Nail bed and skin defect (white curved line indicates the border of the lunula). (B) Nail bed harvesting from the big toe (white curved line indicates the border of the lunula). (C) After 24 months.
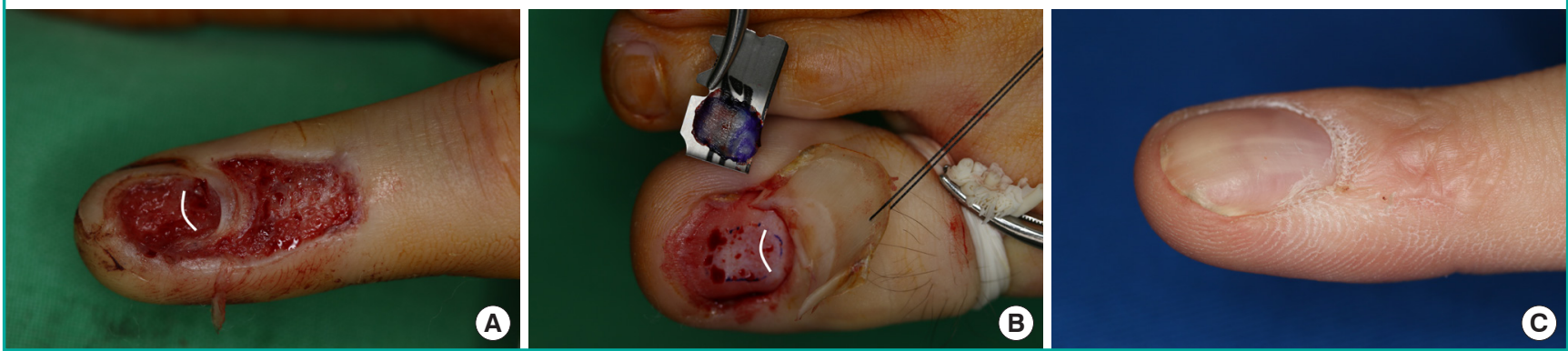

Fig. 3. Coverage with flap and nail bed graft

Case 2. (A) Crush injury of a fingertip with exposure of the distal phalanx (dorsal view). (B) First stage: digital artery-pedicled subcutaneous flap to cover the exposed bone (white curved arrow indicates the rotational direction for covering the exposed bone). (C) Second stage: placement of the nail bed and skin graft. Area of nail bed (yellow arrow) and skin (white arrow). (D) Outcome after 14 months, reconstructed finger (white arrow) and unaffected contralateral finger. (E) Donor site after 14 months.
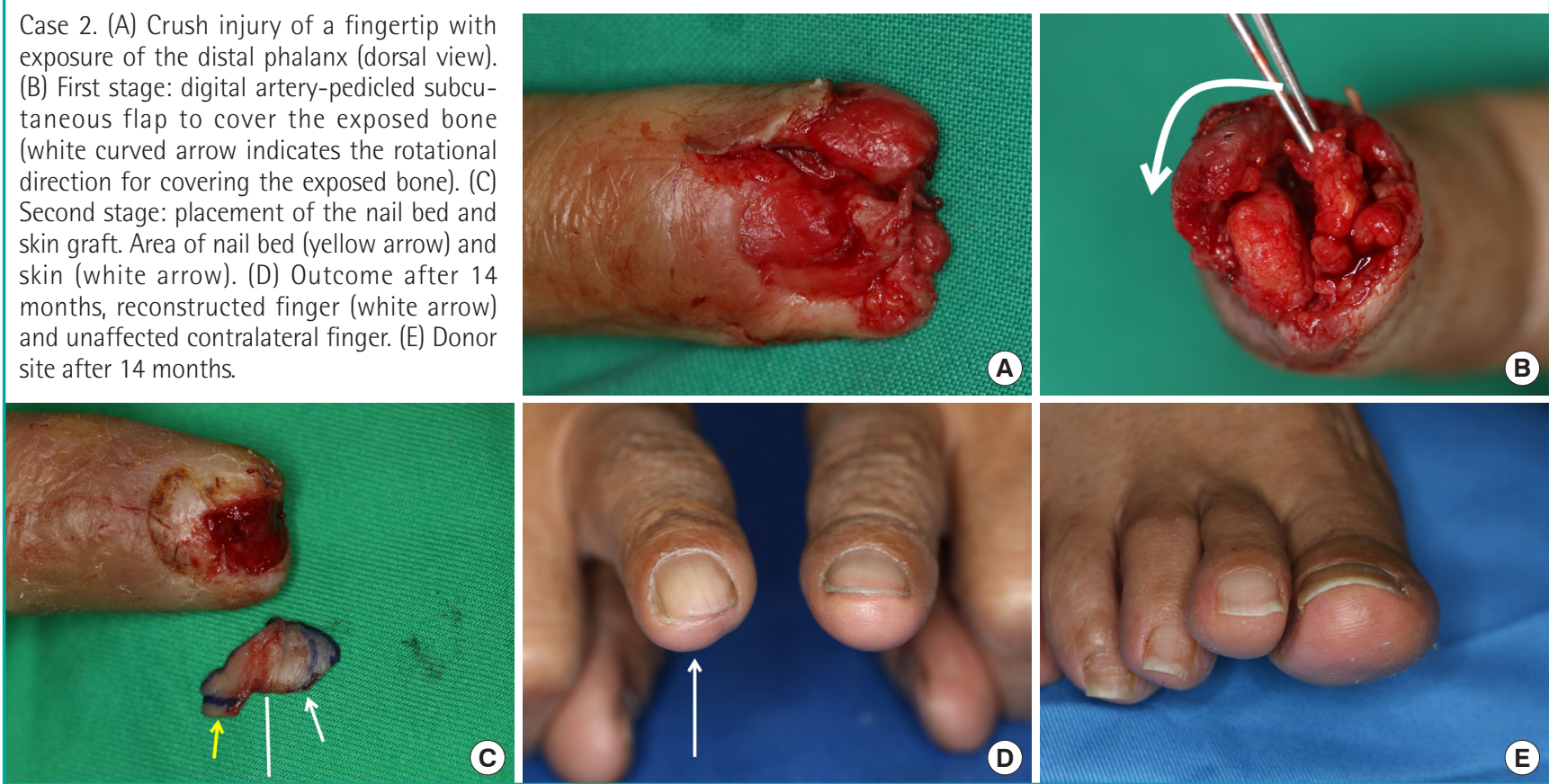

(C)
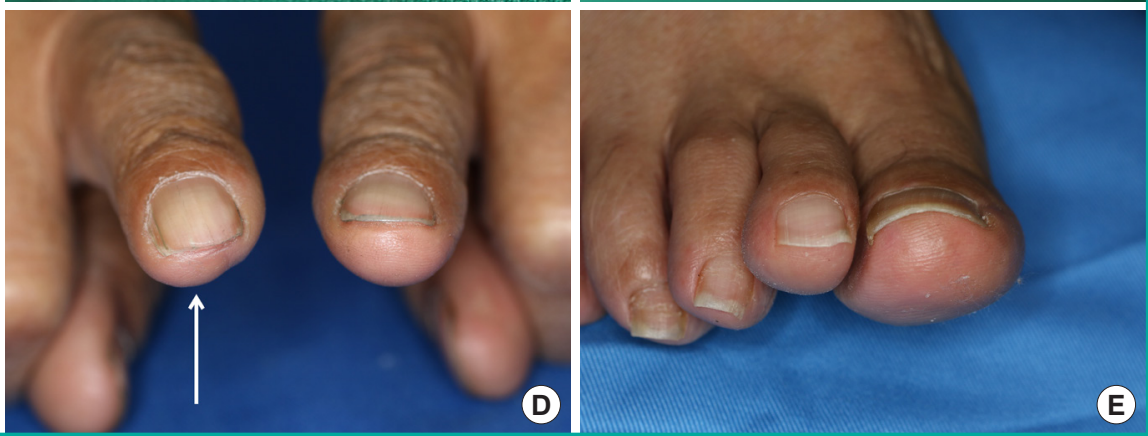

The flap was repositioned at the fingertip to cover the exposed bone (Fig. 3B). After 3 weeks, the flap survived without any notable complications. We simultaneously harvested a nail bed graft and a skin graft from the big toe that were designed to fit each zone, maintaining continuity (Fig. 3C). At a 14-month follow-up (Fig. 3D), the new nail was evaluated as excellent. The big toe that was used as the donor site for the nail showed no deformities compared to the contralateral big toe (Fig. 3E). The volume of the volar pulp (donor site of the digital artery-pedicled subcutaneous flap) was not noticeably reduced compared to that of the contralateral finger (Fig. 3).

\section{DISCUSSION}

The nail bed is composed of the germinal matrix proximally, which produces the majority of cells that become the nail plate by gradient parakeratosis [10]. The sterile matrix distal to this structure serves to anchor the nail plate to the periosteum of the distal phalanx during distal growth by adding cells to the volar surface of the nail plate $[11,12]$. The role of the sterile matrix differs from that of the germinal matrix in nail production; therefore, it is crucial to reconstruct the area of the germinal matrix and sterile matrix separately, which means that replacement of the germinal matrix with the sterile matrix is not recommended. The sterile matrix has longitudinal ridges that aid attachment by increasing the surface area, and these ridges determine the direction of longitudinal growth $[13,14]$. Therefore, it is essential to match the direction of the defect during harvesting and grafting of a nail bed. A smooth, flat surface is necessary for the growth of a normal nail plate, and these unique structures of the 


\section{Fig. 4. Patient with germinal matrix involvement}

(A) Nail bed injury accompanied by germinal matrix involvement. (B) Outcome after 6 months.
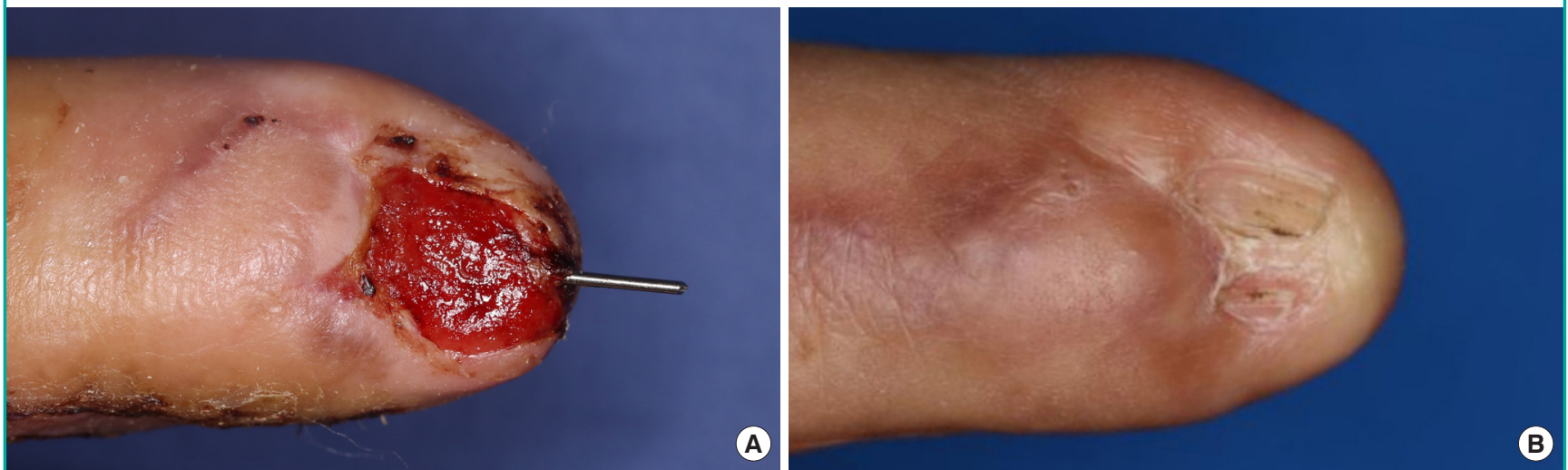

Fig. 5. Patient with a bone injury

(A) Amputation of a fingertip with bone injuries requiring two-stage reconstruction. (B) Fracture of the distal phalanx leading to irregularities on the bony surface. (C) Placement of a nail bed graft after bone coverage with a fascial flap. (D) Six months after surgery, comparison with the contralateral finger (white arrow indicates the injured finger).
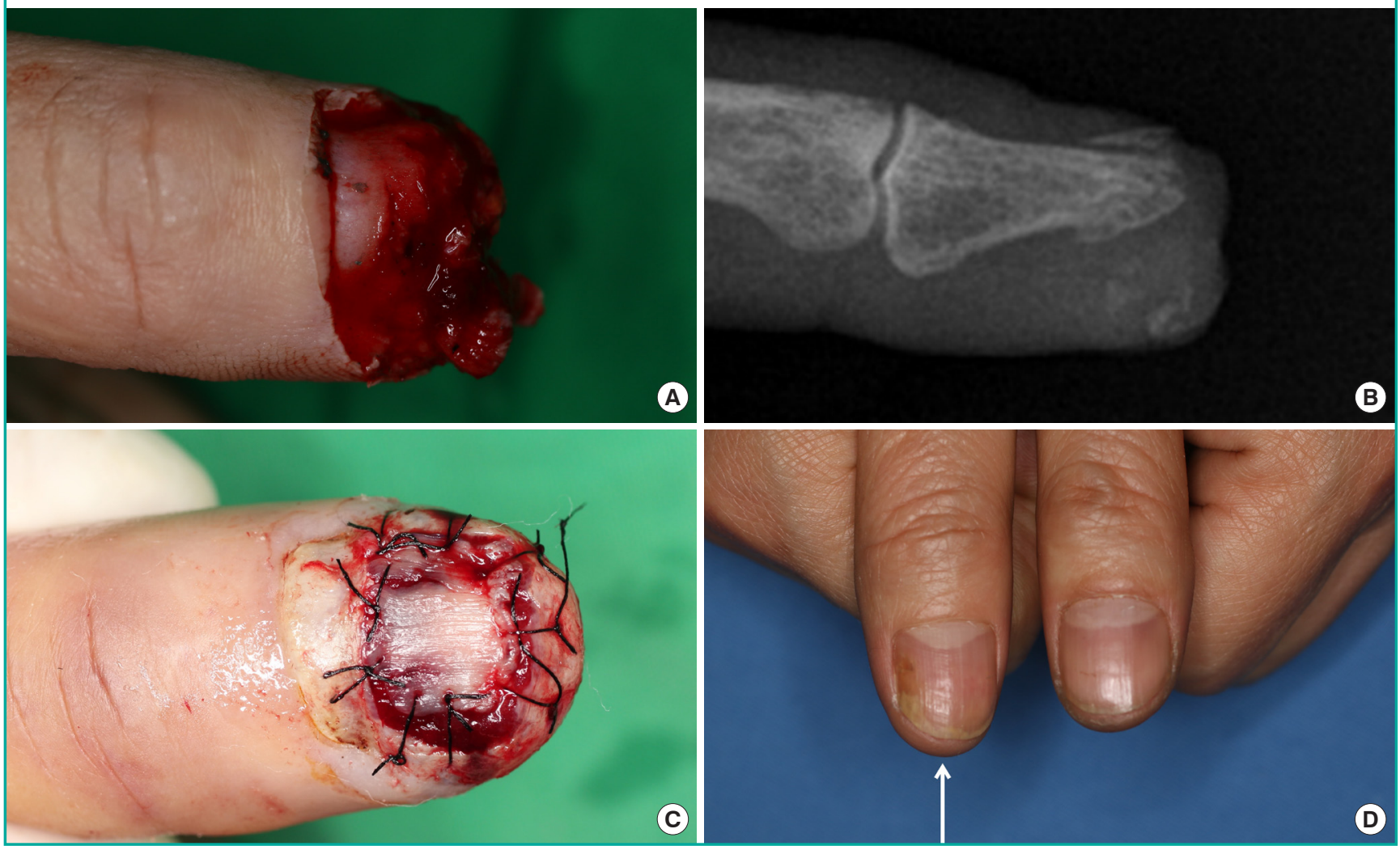

nail bed make reconstruction challenging $[11,15,16]$.

Historically, several efforts have been made to restore the structures of the nail bed. In 1983, Shepard [17] performed 31 cases of split-thickness nail bed grafts, and Saito et al. [18] reported 11 cases of full-thickness nail bed grafts. In 1984, Zook et al. [19] reported long-term follow-up of 184 cases of nail bed repair. In 1988, Koshima et al. [20] performed two cases of free

vascularized nail transfer from a big toe. In 2013, Hwang et al. [21] reported 14 cases of nail bed grafts combined with V-Y advancement flaps and six cases using abdominal flaps. In 2019, Lee et al. [9] reported nail bed grafts combined with thenar fascial flaps.

Likewise, we tried to reconstruct each area of the nail bed with similar anatomical and physiological features as much as possi- 
ble. The graft was designed to fit each missing area of the germinal matrix, sterile matrix, and skin tissue. However, the results were inconsistent despite these efforts. Even with minor injuries, the outcomes were poor in some cases, while others showed excellent outcomes despite severe crush injuries. Thus, we hypothesized that the type of reconstruction method might affect the outcomes. Nonetheless, no significant differences were found depending on the reconstruction method. However, in patients with damage to the germinal matrix or a large nail bed defect, there was a tendency for scarring and problems with nail production after nail bed grafting, resulting in significant deformities (Fig. 4). The germinal matrix produces approximately $90 \%$ of nail cells, whereas the sterile matrix produces the remaining nail cells; nevertheless, the primary role of the sterile matrix is to attach the nail to the matrix [10-12]. This fact indicates that damage to the germinal matrix has a more significant impact on outcomes than damage to the sterile matrix. Furthermore, among the 11 cases of large defects, nine had a concomitant injury to the germinal matrix. Therefore, it may be the case that large defects are more likely to involve injury to the germinal matrix.

In addition, Zook et al. [19] reported in 1984 that the presence of a distal phalanx shaft or tuft fracture was associated with the occurrence of nail surface irregularities. Since then, it has been traditionally believed that bone continuity provides a smooth framework for the nail bed, which is considered essential for normal nail production. In this study, however, no significant differences in outcomes were observed depending on the involvement of bone injuries, and thin flap coverage of the injured bone followed by nail bed grafting allowed efficient nail production (Fig. 5). These results might be explained by enhanced bone reduction or relatively smooth callus formation. Furthermore, the flap over the bone might have helped provide a smooth framework for the nail bed graft.

This study has some limitations. It was a retrospective comparative study, not a randomized case-control study; therefore, the results may have been affected by selection bias. For this reason, future prospective randomized studies with larger sample sizes are required. Furthermore, it would be worthwhile to compare cases of nail bed defects that healed with secondary intention, with split-thickness skin grafts, and with nail bed grafts.

In conclusion, the outcomes appeared poor when the germinal matrix was involved or the defect was large. However, the reconstruction method, age, timing of surgery, and the presence of bone involvement did not significantly affect the outcomes. Considering all these factors, we can infer that the location and size of a defect have a considerable influence on its prognosis. These experiences will enable a more precise prediction of out- comes depending on the patient's condition, making the results more acceptable to the patient. Moreover, this information will help patients to consider alternative treatment plans when poor outcomes are anticipated, including the use of an artificial dermis instead of a nail bed graft, which can lead to more satisfying results without sacrificing a donor site [22].

\section{NOTES}

\section{Conflict of interest}

No potential conflict of interest relevant to this article was reported.

\section{Ethical approval}

The study was approved by the Institutional Review Board of Gwangmyeong Sungae General Hospital (IRB No. KIRB2019-N-008) and performed in accordance with the principles of the Declaration of Helsinki. Written informed consents were obtained.

\section{Patient consent}

The patients provided written informed consent for the publication and the use of their images.

\section{Author contribution}

Conceptualization: Kim JS, Koh SH, You Y, Kim YW. Data curation: Kim JS, Koh SH, You Y, Roh SY. Formal analysis: Kim JS, Koh SH, You Y, Lee DC, Roh SY. Methodology: Kim JS, Koh SH, You Y, Kim YW, Hong MK. Project administration: Kim JS, Koh SH, You Y, Lee KJ. Visualization: Kim JS, Koh SH, You Y, Kim YW, Lee KJ, Hong MK. Writing - original draft: Kim JS, Koh SH, You Y. Writing - review \& editing: Kim JS, Koh $\mathrm{SH}$, You Y.

\section{ORCID}

Sung Hoon Koh https://orcid.org/0000-0002-8094-2561

Youngkee You https://orcid.org/0000-0002-0885-3150

Yong Woo Kim https://orcid.org/0000-0002-8834-8487

Jin Soo Kim https://orcid.org/0000-0003-3369-2974

Dong Chul Lee https://orcid.org/0000-0003-4211-6901

Si Young Roh https://orcid.org/0000-0002-8625-6124

Kyung Jin Lee https://orcid.org/0000-0002-9448-8291

Min Ki Hong https://orcid.org/0000-0002-8587-7420

\section{REFERENCES}

1. Sommer NZ. The perionychium. In: Wolfe SW, Hotchkiss RN, Pederson WC, et al. editors. Green's operative hand sur- 
gery. 7th ed. Philadelphia: Elsevier; 2016. p. 318-37.

2. Clayburgh RH, Wood MB, Cooney WP 3rd. Nail bed repair and reconstruction by reverse dermal grafts. J Hand Surg Am 1983;8(5 Pt 1):594-8.

3. Brown RE, Zook EG, Russell RC. Fingertip reconstruction with flaps and nail bed grafts. J Hand Surg Am 1999;24:34551.

4. Shepard GH. Nail grafts for reconstruction. Hand Clin 1990; 6:79-102.

5. Endo T, Nakayama Y. Microtransfers for nail and fingertip replacement. Hand Clin 2002;18:615-22.

6. Nam SB. The perionychium. In: The Korean Society for Surgery of the Hand, editor. Surgery of the hand. 1st ed. Seoul: Bumoon Education; 2014. p. 155-61.

7. Shepard GH. Management of acute nail bed avulsions. Hand Clin 1990;6:39-56.

8. Tran LE, Berry GJ, Fee WE Jr. Split-thickness skin graft attachment to bone lacking periosteum. Arch Otolaryngol Head Neck Surg 2005;131:124-8.

9. Lee KJ, Kim YW, Kim JS, et al. Nail bed defect reconstruction using a thenar fascial flap and subsequent nail bed grafting. Arch Plast Surg 2019;46:57-62.

10. Zaias N. Embryology of the human nail. Arch Dermatol 1963;87:37-53.

11. De Berker D, Mawhinney B, Sviland L. Quantification of regional matrix nail production. Br J Dermatol 1996;134: 1083-6.
12. Johnson M, Shuster S. Continuous formation of nail along the bed. Br J Dermatol 1993;128:277-80.

13. Lewis BL. Microscopic studies of fetal and mature nail and surrounding soft tissue. AMA Arch Derm Syphilol 1954; 70:733-47.

14. Baden HP. Regeneration of the nail. Arch Dermatol 1965; 91:619-20.

15. Brucker MJ, Edstrom L. The use of grafts in acute and chronic fingernail deformities. J Hand Surg Am 2002;2:14-20.

16. Zook EG, Van Beek AL, Russell RC, et al. Anatomy and physiology of the perionychium: a review of the literature and anatomic study. J Hand Surg Am 1980;5:528-36.

17. Shepard GH. Treatment of nail bed avulsions with splitthickness nail bed grafts. J Hand Surg Am 1983;8:49-54.

18. Saito H, Suzuki Y, Fujino K, et al. Free nail bed graft for treatment of nail bed injuries of the hand. J Hand Surg Am 1983;8:171-8.

19. Zook EG, Guy RJ, Russell RC. A study of nail bed injuries: causes, treatment, and prognosis. J Hand Surg Am 1984;9: 247-52.

20. Koshima I, Soeda S, Takase T, et al. Free vascularized nail grafts. J Hand Surg Am 1988;13:29-32.

21. Hwang E, Park BH, Song SY, et al. Fingertip reconstruction with simultaneous flaps and nail bed grafts following amputation. J Hand Surg Am 2013;38:1307-14.

22. Sugamata A. Regeneration of nails with artificial dermis. J Plast Surg Hand Surg 2012;46:191-4. 